\title{
ANALISIS BIAYA OPERASIONAL KENDARAAN (BOK) ANGKUTAN ANTAR KOTA ANTAR PROVINSI (AKAP) DI GORONTALO
}

\author{
St Maryam H ${ }^{1}$, Lambang Basri Said ${ }^{2}$, Dahlina A.Adju \\ Dosen Magister Teknik Sipil Pascasarjana Universitas Muslim Indonesia \\ JL Urip sumohardjo no 225, maryammaladia@gmail.com \\ Dosen Magister Teknik Sipil Pascasarjana Universitas Muslim Indonesia \\ JL Urip sumohardjo no 225, elbasriumi@yahoo.com \\ Ka.si Irigasi, Sungai, Rawa, dan Pantai Bidang SDA Dinas PU dan Penataan Ruang Kota \\ Gorontalo \\ Kota Gorontalo,Telp.(0435) 824630,Email :Dahlina75@yahoo.com
}

\section{ABSTRAK}

Salah satu komponen utama biaya pengguna jalan adalah Biaya Operasi Kendaraan (Vehicle Operating Cost). Biaya Operasi Kendaraan merupakan biaya yang dibutuhkan untuk mengoperasikan kendaraan pada suatu kondisi lalu lintas dan jalan untuk suatu jenis kendaraan. Berdasarkan hal tersebut di atas, maka dalam penelitian ini difokuskan pada Biaya Operasi Kendaraan (BOK) Angkutan Antar Kota Antar Provinsi (AKAP) Gorontalo. Penelitian ini bertujuan untuk [1] Menganalisis biaya Tetap per tahun Bus Nyiur Trans Manado ke Gorontalo pada Angkutan Antar Kota Antar Provinsi (AKAP) Di Gorontalo. [2] Menganalisis biaya tidak tetap per tahun Bus Nyiur Trans Manado ke Gorontalo pada Angkutan Antar Kota Antar Provinsi (AKAP) Di Gorontalo. Penelitian yang dilakukan adalah penelitian terapan dengan mempergunakan beberapa pengetahuan ilmiah yakni teori-teori atau studi kepustakaan yang telah dikemukakan menyangkut judul penelitian. Penelitian ini merupakan penelitian non eksperimental yang sifatnya deskriptif kualitatif dan kuantitatif. Jenis studi kasus dengan pengamatan langsung di lapangan yang ditujukan untuk menentukan kinerja pelayanan dan biaya transportasi angkuan kota dalam provinsi (AKAP) Kota Gorontalo. Dari hasil analisis dan pembahasan maka dapat ditarik beberapa kesimpulan yakni [1] biaya tetap per tahun Bus Nyiur Trans Manado - Gorontalo pada Angkutan Antar Kota Antar Provinsi (AKAP) Di Gorontalo adalah sebesar Rp. 49.586.000.00,- / th. [2] biaya tidak tetap per tahun Bus Nyiur Trans Manado - Gorontalo pada Angkutan Antar Kota Antar Provinsi (AKAP) Di Gorontalo adalah sebesar Rp. 66.119.580.00,- / th.

Kata Kunci : BOK, AKAP, Nyiur Trans

\section{PENDAHULUAN}

\subsection{Latar Belakang}

Indikator keberhasilan pembangunan di Kota Gorontalo sangat dipengaruhi oleh sistem transportasi, karena transportasi merupakan urat nadi bagi kehidupan dengan fungsi sebagai penggerak, pendorong dan penunjang pembagunan di wilayah ini. Peranan sistem jaringan transportasi sebagai prasarana perkotaan mempunyai dua tujuan utama yaitu sebagai alat untuk mengarahkan pembangunan perkotaan dan sebagai prasarana bagi pergerakan orang dan barang yang timbul akibat adanya kegiatan di daerah perkotaan.

Pertumbuhan ekonomi yang cukup signifikan di Kota Gorontalo dalam era otonomi telah mendorong pesatnya laju pembangunan di segala bidang terutama dalam bidang sosial ekonomi, dengan kondisi yang demikian menjadikan aktivitas masyarakat sehari-hari semakin meningkat, sehingga menuntut tersedianya sistem transportasi yang memadai dan 
mampu menjadi penunjang dan pendukung kegiatan secara optimal karena transportasi merupakan alat untuk mengatasi jarak, waktu dan biaya.

Transportasi darat di Kota Gorontalo tersedia dengan jumlah yang memadai. Kondisi jalan 90 persen konstruksi hotmix dalam kondisi baik. Jaringan jalan memegang peranan yang sangat penting untuk melancarkan arus transportasi dan merupakan hal yang tidak dapat dipisahkan dengan kebutuhan manusia karena selalu dibutuhkan dalam pendistribusian bahan, pergerakan aktifitas manusia maupun barang.

Transportasi harus mampu memberikan kemudahan bagi seluruh lapisan masyarakat dalam segala kegiatannya di semua lokasi yang berbeda dan tersebar dengan karakteristik yang berbeda pula. Untuk mewujudkan tujuan tersebut, pembangunan prasarana transportasi jalan dilakukan searah dengan perkembangan kota atau wilayah. Transportasi yang aman dan lancar selain mencerminkan keteraturan kota juga mencerminkan kelancaran kegiatan perekonomian kota.

Salah satu komponen utama biaya pengguna jalan adalah Biaya Operasi Kendaraan (Vehicle Operating Cost). Biaya Operasi Kendaraan merupakan biaya yang dibutuhkan untuk mengoperasikan kendaraan pada suatu kondisi lalu lintas dan jalan untuk suatu jenis kendaraan.

Berdasarkan hal tersebut di atas, maka dalam penelitian ini difokuskan pada Biaya Operasi Kendaraan (BOK) Angkutan Antar Kota Antar Provinsi (AKAP) Gorontalo.

\subsection{Rumusan Masalah}

Berdasarkan uraian pada latar belakang maka rumusan masalah yang akan dikaji dalam penelitian ini adalah:

1. Berapa besar biaya tetap per tahun Bus Nyiur Trans Manado - Gorontalo pada Angkutan Antar Kota Antar Provinsi (AKAP) Di Gorontalo?

2. Berapa besar biaya tidak tetap per tahun Bus Nyiur Trans Manado - Gorontalo pada Angkutan Antar Kota Antar Provinsi (AKAP) Di Gorontalo?

\subsection{Tujuan Penelitian}

Dari rumusan masalah di atas maka dapat dikemukakan beberapa tujuan penelitian yang ingin dicapai, yaitu:

1. Menganalisis biaya Tetap per tahun Bus Nyiur Trans Manado ke Gorontalo pada Angkutan Antar Kota Antar Provinsi (AKAP) Di Gorontalo.

2. Menganalisis biaya tidak tetap per tahun Bus Nyiur Trans Manado ke Gorontalo pada Angkutan Antar Kota Antar Provinsi (AKAP) Di Gorontalo.

\section{METODOLOGI PENELITIAN}

\subsection{Rancangan Penelitian}

Penelitian yang dilakukan adalah penelitian terapan dengan mempergunakan beberapa pengetahuan ilmiah yakni teori-teori atau studi kepustakaan yang telah dikemukakan menyangkut judul penelitian. Penelitian ini merupakan penelitian non eksperimental yang sifatnya deskriptif kualitatif dan kuantitatif. Jenis studi kasus dengan pengamatan langsung di lapangan yang ditujukan untuk menentukan kinerja pelayanan dan biaya transportasi angkuan kota dalam provinsi (AKAP) Kota Gorontalo.

\subsection{Lokasi dan Waktu Penelitian}

Lokasi Penelitian berada di Kota Gorontalo Provinsi Gorontalo. Waktu penelitian dilaksanakan mulai bulan Februari 2016 diawali dengan studi pendahuluan, kemudian dilanjutkan dengan observasi pada bulan Desember 2016 dan Januari 2017. 


\subsection{Teknik Pengumpulan Data}

Pengumpulan data dalam penelitian ini terdiri dari pengumpulan data primer dan data sekunder. Data primer diperoleh dari sejumlah responden maupun informan serta pengamatan langsung di lapangan melalui observasi dan wawancara kepada pengemudi angkutan umum regional khusunya pengemudi Angkutan Antar Kota Antar Provinsi (AKAP) sedangkan data sekunder diperoleh dari dokumen-dokumen serta referensi yang dianggap relevan dengan penelitian ini.

\subsubsection{Data primer}

a. Survey/observasi langsung.

Data arus lalu lintas dilakukan dengan cara manual pada titik yang telah ditetapkan. Waktu pelaksanaan pencatatan dimulai pada waktu, hari dan tanggal yang ditetapkan. Alat survey yang digunakan adalah jam tangan digital, formulir survey, dan alat tulis.

b. Wawancara langsung.

1) Pengumpulan data dilakukan dengan cara pengumpulan informasi dan komentar dari stakeholder yang terkait peran dan fungsi dan tugas dengan objek yang diteliti. Pihak-pihak yang dimaksud adalah petugas dari Dinas Perhubungan.

2) Kegiatan pengumpulan data yang meliputi data biaya tetap dan biaya tidak tetap operasi kendaraan melalui wawancara yakni:

a) Biaya depresiasi kendaraan: harga kendaraan baru, harga kendaraan sekarang, usia kendaraan.

b) Biaya awak kendaraan.

c) Biaya asuransi.

d) Biaya overhead: biaya perizinan, biaya pajak kendaraan dan biaya KIR.

\subsubsection{Data sekunder}

Data sekunder yang dibutuhkan yaitu:

a. Data kondisi jalan yakni data geometrik jalan meliputi data panjang jalan, tipe jalan, lebar jalan, lebar bahu jalan dan kondisi medan (lintasan trayek)

b. Data unit-unit biaya, yaitu: harga bahan bakar (Rp/liter), harga minyak pelumas (Rp/liter).

\subsection{Teknik Analisis Data}

Tindak lanjut terhadap data yang telah dikumpulkan melalui teknik pengumpulan data adalah proses analisis data. Data yang diperoleh atau yang dikumpulkan,akan dianalisis sesuai dengan tujuan penelitian. Dalam menganalisis Biaya Operasi Kendaraan digunakan model perhitungan BOK berdasarkan Pedoman Perhitungan BOK Puslitbang Prasarana Transportasi yang telah disesuaikan dengan kondisi di Indonesia serta adaptasi beberapa persamaan dan parameter yang ada di HDM IV tahun 2000, dengan mengacu pada pedoman dari Badan Standardisasi Nasional No. 8 tahun 2000, serta model perhitungan yang bersumber dari Lembaga Afliasi Penelitian dan Industri Institut Teknologi Bandung (LAPI-ITB), 1996.

\section{HASIL PENELITIAN}

\subsection{Analisis Biaya Operasi Kendaraan}

Perhitungan BOK didasarkan pada asumsi bahwa kendaraan adalah kendaraan baru dan harga-harga adalah yang berlaku saat ini, jadi biaya operasi kendaraan yang diperoleh adalah berlaku pada saat ini sampai dengan umur ekonomis kendaraan 5 tahun (teknis). Secara garis besarnya perhitungan BOK ini terdiri dari biaya tetap (fixed cost) dan biaya tidak tetap (variable cost). Adapun jenis kendaraan yang diteliti dalam penelitian ini adalah sebagai berikut: 


\subsubsection{Spesifikasi ISUZU ELF NKR 55 MICROBUS LWB}

Harga : Rp.290.000.000.00,-

*) Estimasi harga on the road 2013 dan locco jakarta.

*) Harga dapat berubah-ubah tanpa pemberitahuan terlebih dahulu. Tabel 1. Dimensi kendaraan ISUZU ELF NKR 55

\begin{tabular}{|l|r|r|}
\hline Panjang Keseluruhan & 5505 & $(\mathrm{~mm})$ \\
\hline Lebar Keseluruhan & 1695 & $(\mathrm{~mm})$ \\
\hline \hline Tinggi Keseluruhan & 2127 & $(\mathrm{~mm})$ \\
\hline \hline Jarak Terendah & 190 & $(\mathrm{~mm})$ \\
\hline \hline Jarak Poros Roda & 3405 & $(\mathrm{~mm})$ \\
\hline \hline Jarak Pijak Roda Depan & 1425 & $(\mathrm{~mm})$ \\
\hline \hline Jarak Pijak Roda Belakang & 1405 & $(\mathrm{~mm})$ \\
\hline Seating Capacity & 20 & $($ person) \\
\hline Front Axle Capacity & & $(\mathrm{kg})$ \\
\hline Rear Axle Capacity & & $(\mathrm{kg})$ \\
\hline
\end{tabular}

Tabel 26. Data mesin kendaraan ISUZU ELF NKR 55

\begin{tabular}{|l|r|r||}
\hline Model/Tipe & 4JB1-TC & \\
\hline \hline Sistem injeksi bahan bakar & & \\
\hline Isi silinder & 2771 & (cc) \\
\hline Tenaga maksimum & $101 / 3400$ & $(\mathrm{PS} / \mathrm{rpm})$ \\
\hline Torsi maksimum & $22.5 / 2000-3200$ & $(\mathrm{Kgm} / \mathrm{rpm})$ \\
\hline \hline Garis tengah $\mathrm{x}$ langkah & $93 \times 102$ & $(\mathrm{~mm})$ \\
\hline Kapasitas Tangki & & (liter) \\
\hline
\end{tabular}

Tabel 3. Ukuran ban dan velg kendaraan ISUZU ELF NKR 55

\begin{tabular}{|l|c|}
\hline Ukuran ban & - \\
\hline Bahan & - \\
\hline Ban Depan & Single 225/70/R16C \\
\hline Ban Belakang & Single 225/70/R16C \\
\hline
\end{tabular}

Tabel 4. Kelengkapan standar kendaraan ISUZU ELF NKR 55

\begin{tabular}{|l|c|c|}
\hline Kursi supir & - & \\
\hline \hline Seat belt & Yes & \\
\hline \hline Accu & $12-75$ & $(\mathrm{~V}-\mathrm{AH})$ \\
\hline \hline Altertnator & $12-60$ & $(\mathrm{~V}-\mathrm{A})$ \\
\hline \hline Kapasitas Tangki & 75 & $($ liter $)$ \\
\hline \hline Max. Gradeability & 34 & $(\%)$ \\
\hline Max. Speed & 102 & $(\mathrm{Km} / \mathrm{h})$ \\
\hline Clutch Size & - & $(\mathrm{mm})$ \\
\hline
\end{tabular}


Tabel 5. Ukuran berat kendaraan ISUZU ELF NKR 55

\begin{tabular}{|l|c|c|}
\hline Curb Weight (berat kosong) & - & $(\mathrm{kg})$ \\
\hline \hline Gross Vehicle Weight (berat total) & - & $(\mathrm{kg})$ \\
\hline
\end{tabular}

Tabel 6. Data Transmisi kendaraan ISUZU ELF NKR 55

\begin{tabular}{|l|r|}
\hline Model & MSB5M \\
\hline C & \\
\hline gigi 1 & 5.594 \\
\hline gigi 2 & 2.814 \\
\hline gigi 3 & 1.660 \\
\hline gigi 4 & 1.000 \\
\hline gigi 5 & 0.794 \\
\hline gigi 6 & \\
\hline \hline gigi 7 & \\
\hline gigi 8 & \\
\hline Rev & \\
\hline Final Gear Ratio & 5.334 \\
\hline
\end{tabular}

Tabel 7. Fitur dan standar kendaraan ISUZU ELF NKR 55

\begin{tabular}{|l|c|}
\hline Air Conditioning & No \\
\hline \hline Radio CD+MP3 & Yes \\
\hline Power Steering & Yes \\
\hline
\end{tabular}

\section{a. Optional Tambahan}

1. AC Nippon Denso Model M-10 Rp. 21.000.000,-

2. Kaca Bounding Geser ( Rayban Hitam / Euro Grey) Rp. 3.500.000,-

3. Bumper depan dan Fog Lamp standart Adiputro Rp. 2.500.000,-

4. Gorden Adiputro Rp. 3.500.000,-

5. Tambahan Bangku 1 baris Rp. 3.000.000,-

6. Inverter dan Colokan Listrik Rp. 1.500.000,-

7. Audio Set: DVD, TV LED 19", 2 set speaker, 1 pcs power, 1 pes subwoofer Rp. 9.500.000,-

8. Instalasi Audio Set (Apabila Bawa Sendiri) Rp. 1.500.000,-

9. Pintu Sliding Rp. 9.000.000,-

Sumber : http://isuzu-ki.blogspot.co.id/2014/04/harga-dan-spesifikasi-isuzu-elf-nkr-55 16.html

\subsubsection{Analisis BOK Tetap per Tahun}

Perhitungan BOK Tetap per Tahun untuk semua trayek sama dikarenakan jenis kendaraan yang digunakan adalah sama yakni IZUSU NKR Long Wheel Base tahun 2014, dengan rincian perhitungan biaya tetap sebagai berikut :

1. Biaya Penyusutan (Depresiasi) Kendaraan per Tahun:

$\mathrm{BP} \quad=(\mathrm{HK}-\mathrm{NR}) / \mathrm{MP}$

$=(290.000 .000)-(20 \% \times 290.000 .000) / 7$

$=((290.000 .000)-(58.000 .000)) / 7$

$=$ Rp. 33.142.857.14, $-/$ th. 
2. Biaya Bunga Modal

Pembelian kendaraan diasumsikan secara kredit dengan bunga bank 13,5\% per tahun, dengan jangka waktu kredit 4 tahun.

$\mathrm{BBMo}=(\mathrm{n}+1) / 2 \times(\mathrm{Hk} \times \mathrm{i}) / \mathrm{MP}$

$$
\begin{aligned}
& =(4+1) / 2 \times(290.000 .000 \times 13,5 \%) / 7 \\
& =\text { Rp.13.982.142.86,-/th. }
\end{aligned}
$$

3. Biaya administrasi kendaraan terdiri atas:

a. Biaya pajak kendaraan (STNK) per tahun Rp. 2.060.000/ th.

b. Biaya kir per tahun Rp. $120.000 /$ th.

c. Biaya ijin usaha angkutan Rp. - / th.

d. Biaya asuransi jasa raharja Rp. 276. $000 /$ th.

e. Biaya ijin trayek

Total biaya administrasi

$\frac{\text { Rp. } 5.000 / \text { th }+}{\text { Rp. } 2.461 .000 .00 / \text { th. }}$

Berdasarkan biaya-biaya tetap diatas, maka dapat ditentukan besarnya biaya tetap operasional kendaraan per tahun yaitu:

Total BOK tetap/th $=\mathrm{BP} /$ th + BBMo $/$ th + Admin/ th

$=$ Rp. 33.142.857.14/th + Rp. 13.982.142.86/th + Rp. 2.461.000/th.

$=$ Rp. 49.586.000 / th

\subsubsection{Analisis BOK Tidak Tetap per Tahun}

Analisis biaya operasi kendaraan tidak tetap merupakan seluruh biaya yang dikeluarkan sehubungan dengan pengoperasian kendaraan yang besarannya dipengaruhi oleh lintasan dan potensi penumpang. Berikut rincian perhitungan BOK tidak tetap pada trayek.

Rute : Trans Sulawesi Provinsi Gorontalo - Manado

1. Biaya Awak Kendaraan

Awak kendaraan pada penilitian ini diasumsikan hanya pengemudi tanpa kondektur, dihitung dengan rumus :

$\mathrm{BAK} / \mathrm{th}=$ Gaji/hr $\mathrm{J} \mathrm{JHO} / \mathrm{th}(5 \mathrm{hr} \times 4$ minggu $\times 12 \mathrm{bln})$.

$=$ Rp. $150.000 \times 240$

$=$ Rp. 36.000.000/th.

2. Biaya Bahan Bakar Minyak

Biaya bahan bakar minyak yang digunakan adalah solar dengan harga Rp.7.500 / liter. Pada trayek Trans Sulawesi Gorontalo - Manado Panjang trayeknya adalah 400 Km (8 jam 37 menit). Dimana kendaraan jenis ini konsumsi bahan bakarnya adalah 1 liter : $10 \mathrm{Km}$, dihitung dengan rumus :

$\mathrm{BBBM} / \mathrm{th}=\mathrm{BBM} / \mathrm{hr} \times \mathrm{JHO} / \mathrm{th}$

1 liter $=10 \mathrm{Km}$

Konsumsi $\mathrm{BBM}=(400 \mathrm{Km} / 10 \mathrm{Km}) \times 2$ (jumlah operasi per hari)

$=80 \mathrm{lt} / \mathrm{hr}$

$\mathrm{BBBM} / \mathrm{th}=(\mathrm{Rp} .7 .500 \times 1,3 \mathrm{lt} / \mathrm{hr}) \times$ panjang trayek

$=$ Rp. $7.500 \times 400$

$=$ Rp. 3.000.000.00,-/th.

3. Biaya Ban

Jumlah ban yang digunakan untuk angkutan mobil penumpang umum 4 (empat) ban baru dengan daya tempuh $25.000 \mathrm{Km}$. Adapun penggunaan ban yang dimaksud adalah ban luar dan ban dalam, dihitung dengan rumus :

$\mathrm{BB} / \mathrm{th}=1 / \mathrm{DT} \times \mathrm{JPB} \times \mathrm{JT} \times \mathrm{HB}$

Jarak tempuh per tahun $=\mathrm{JT} /$ hari $\mathrm{x} \mathrm{JHO}$ 
$\mathrm{BB}=(1 / 25.000) \times 4 \times(400 \mathrm{Km} / \mathrm{hr} \times 240)$

$=(1 / 25.000) \times 4 \times 96.000 \mathrm{Km} / \mathrm{th}$

$=15.36$ unit $/$ th.

Jadi biaya pemakaian ban per tahun:

$\mathrm{BB} / \mathrm{th}=15.36$ unit $/$ th $\times$ Rp. $963.000 /$ unit

$=$ Rp. 14.791.680.00/th.

4. Biaya Pemakaian Aki

Daya aki diasumsikan selama dua tahun, sehingga biaya pemakaian aki adalah :

$\mathrm{BPA} /$ th $=\mathrm{JPA} /$ th $\mathrm{xHA} /$ unit

$\mathrm{BPA} / \mathrm{th}=1 / 2 \times \mathrm{Rp} .1 .380 .000$

5. Biaya Servis Kecil

$$
=\text { Rp. } 690.000 / \text { th. }
$$

Servis kecil dilakukan setiap $5000 \mathrm{Km}$, terdiri atas:

a. Biaya bahan

- Oli mesin $=7$ liter x Rp. $55.000 /$ liter $=$ Rp. 385.000

- Gemuk $=0,5 \mathrm{~kg}$ x Rp. $54.500 / \mathrm{kg}=$ Rp. 27.250

- Minyak rem =0,25 liter x Rp. $38.500 /$ liter $\quad=$ Rp. 9.625

$\begin{array}{cl}\text { - Filter Solar }=1 / 2 \text { liter } x \text { Rp. } 5.500 / \text { liter } & =\text { Rp. 2.750 + } \\ \text { Total biaya servis kecil } & =\text { Rp. 424.625.00,- }\end{array}$

Dengan jarak tempuh 96,000 kilometer per tahun maka servis kecil dilakukan 19 kali dalam setahun, sehingga total biaya servis kecil per tahun adalah $19 \times$ Rp. $424.625=$ Rp. 8.152.800.00,-/th.

6. Biaya Servis Besar

Servis besar dilakukan setiap $40.000 \mathrm{Km}$, terdiri atas:

a. Biaya bahan

- Oli Mesin = 7 liter x Rp. $55.000 /$ liter = Rp. 385.000

- Oli Gardan = 3,5 liter x Rp. $35.000 /$ liter $=$ Rp. 122.500

- Oli Transmisi $=3$ liter $x$ Rp. $55.000 /$ liter $=$ Rp. 165.000

- Gemuk $=0,25 \mathrm{~kg} \times \mathrm{Rp} .54 .500 / \mathrm{Kg} \quad=\mathrm{Rp} .13 .625$

- Filter (oli + udara) $=1$ buah x Rp. $55.000=$ Rp. 55.000

- Filter Solar $=2$ liter $x$ Rp. $5.500 \quad=\underline{\text { Rp. } 11.000}$

Total biaya servis besar $=\mathrm{Rp} .752 .125$

Dengan jarak tempuh 96,000 kilometer per tahun maka servis besar dilakukan 2 kali dalam setahun, sehingga biaya yang disiapkan untuk servis besar per tahunnya adalah

$2 \times$ Rp. 752.125 = Rp. 1.805.100.00,- $/$ th.

7. Biaya Cuci Bus

Cuci bus dilakukan sekali seminggu, sehingga biaya cuci bus per tahun dihitung dengan rumus:

$\mathrm{BCB}=4 \times 12 \times \mathrm{Rp} .35 .000$

$=$ Rp. 1.680.000/th.

Berdasarkan biaya-biaya tidak tetap di atas, maka dapat ditentukan besarnya biaya total tidak tetap operasi kendaraan per tahun yaitu:

Total BOK tidak tetap $/$ th $=\mathrm{BAK}+\mathrm{BBM}+\mathrm{BB}+\mathrm{BPA}+\mathrm{BSK}+\mathrm{BSB}+\mathrm{BCB}$.

$=$ Rp.36.000.000+Rp. 3.000.000+Rp. $14.791 .680+$ Rp. $690.000+$ Rp. 8.152.000 + Rp.1.805.100 + Rp. 1.680.000.

$=$ Rp. 66.119.580.00,-/th. 


\section{KESIMPULAN}

Berdasarkan hasil penelitian dan pembahasan yang telah diuraikan pada bab sebelumnya, maka dapat disimpulkan sebagai berikut:

1. biaya tetap per tahun Bus Nyiur Trans Manado - Gorontalo pada Angkutan Antar Kota Antar Provinsi (AKAP) Di Gorontalo adalah sebesar Rp. 49.586.000.00,- / th.

2. biaya tidak tetap per tahun Bus Nyiur Trans Manado - Gorontalo pada Angkutan Antar Kota Antar Provinsi (AKAP) Di Gorontalo adalah sebesar Rp. 66.119.580.00,- / th.

\section{SARAN}

Berdasarkan kesimpulan yang telah diuraikan di atas, maka ada beberapa saran yang dapat diajukan. Untuk mengoptimalkan kembali penggunaan Jalur Trans Sulawesi sebaiknya dilakukan hal-hal sebagai berikut:

1. Kelengkapan fasilitas jalan terutama kondisi rambu lalu lintas, marka jalan dan lampu penerangan jalan harus dilengkapi baik dari segi penempatannya maupun perawatannya, serta peningkatan prasarana di sepanjang Jalur Trans Sulawesi.

2. Penerapan kebijakan transportasi hendaknya dilakukan dengan koordinasi yang baik dari berbagai pihak yakni Dinas Perhubungan, Dinas Pekerjaan Umum, Dinas Tata Kota, Bappeda serta polisi lalu lintas terutama para pelaku transportasi.

3. Untuk penelitian selanjutnya perlu diteliti kinerja pelayanan angkutan umum angkutan kota antar provinsi

\section{UCAPAN TERIMA KASIH}

Penulis mengucapkan terima kasih kepada Rekan-rekan Dinas Pekerjaan Umum Kota Gorontalo Kabupaten Gorontalo yang telah memberi dukungan financial terhadap penelitian ini. Serta terima kasih banyak kepada Dr. Ir. Hj St Maryam H.,MT dan Ir. H. Lambang Basri Said.,MT.,Ph.D selaku Ketua Pembimbing dan Anggota Pembimbing yang telah banyak memberi masukan serta arahan demi Penelitian ini. 


\section{DAFTAR PUSTAKA}

1993. Peraturan Pemerintah RI No. 43 Tahun 1993 tentang Prasarana dan Lalu Lintas Jalan, Jakarta, Pemerintah Republik Indonesia.

1994. Kabupaten Road Economic Evaluation Method (KREEM, Jakarta, Departemen Pekerjaan Umum Direktorat Jenderal Bina Marga.

1995, Biaya Operasi Kendaraan (BOK) untuk Jalan Perkotaan di Indonesia, Jakarta, Departemen Pekerjaan Umum Direktorat Jenderal Bina Marga.

1996. Penghitungan Biaya Operasi Kendaraan (BOK). Bandung, Lembaga Afliasi Penelitian dan Industri Institut Teknologi Bandung (LAPI-ITB).

1997. Manual Kapasitas Jalan Indonesia (MKJI), Jakarta, Departemen Pekerjaan Umum.

2004. Undang-Undang RI No. 32 Tahun 2004 tentang Jalan, Jakarta, Pemerintah Republik Indonesia.

2005. Pedoman Perhitungan Biaya Operasi Kendaraan (BOK), Jakarta, Departemen Pekerjaan Umum Puslitbang Prasarana Transportasi.

2005. Studi Biaya Operasional Kendaraan Bermotor, Dinas Lalu Lintas dan Angkutan Jalan Propinsi Jawa Timur.

2009. Undang-undang No. 22 Tahun 2009 tentang Lalu Lintas dan Angkutan Jalan, Jakarta, Pemerintah Republik Indonesia.

Adisasmita, R, 2007. Ekonomi Prasarana Transportasi, buku ajar mahasiswa Pascasarjana Program Studi Teknik Transportasi. Unhas, Makassar.

Asrul, 2007. Pengembangan Model Analisis Tingkat Pelayanan Jalan dikaitkan dengan Biaya Operasi Kendaraan, Unhas Makassar.

Basuki, Y dan Wibowo, T.E. Proceedings Simposium XI FSTPT, 2008. Biaya Operasional Kendaraan sebagai Salah Satu Dasar Penentuan Efisiensi Proyek Transportasi.

Santoso I. 1996. Perencanaan Prasarana Angkutan Umum. Pusat Studi Transportasi dan Komunikasi Institut Teknologi Bandung.

Khisty, Jotin dan Lall, Kent. 2005. Dasar-Dasar Rekayasa Transportasi, jilid 1, Erlangga, Jakarta.

Khisty, Jotin dan Lall, Kent. 2006. Dasar-Dasar Rekayasa Transportasi, jilid 2, Erlangga, Jakarta.

Miro. 1997. Perencanaan Transportasi. Erlangga, Jakarta.

Morlok. Edward K. 1995. Pengantar Teknik dan Perencanaan Transportasi. Erlangga, Jakarta.

Oglesby, C.H dan Hicks, R.G. 1991. Teknik Jalan Raya, jilid 1. Erlangga, Jakarta.

Putranto, L.S. 2007. Rekayasa Lalu Lintas. PT. Indeks, Jakarta.

Simbolon, M. M. 2003. Ekonomi Transportasi. Ghalia Indonesia, Jakarta. 
Sugiyono. 2008. Statistika untuk Penelitian. Alfabeta, Bandung.

Tamin. 2000. Perencanaan dan Permodelan Transportasi. ITB, Bandung. 